\title{
Serum Tumor Necrosis Factor Alpha and High Sensitive C-Reactiveprotein as Biomarkersin Periodontitis in Iraqi Patients with Osteoarthritis
}

\author{
Enas Nihad Muhammad, B.D.S. ${ }^{(1)}$ \\ Saif S. Saliem B.D.S, M.Sc. ${ }^{(2)}$ \\ Enas Razzoqi Naaom B.D.S, M.Sc. P.H.D ${ }^{(3)}$
}

\begin{abstract}
Background: Periodontitis (PD) is well-known chronic disease affecting the periodontal ligament and alveolar bone, Osteoarthritis (OA) is a chronic joint disease with compound reasons characterized by synovial inflammation, subchondral bone remodeling, also the formation of osteophytes, that cause cartilage degradation. Chronic periodontitis and osteoarthritis are considered widely prevalent diseases and related to tissue destruction due to chronic inflammation in general health and oral health. The aim of this study is todetermine the association of chronic periodontitis and osteoarthritits in patients by analysing tumor necrosis factor alpha TNFa and high sensitive c-reactive protein (hsCRP) in the serum.

Materials and Method: A total of 80 patients of both sexes aged 35-50 years, 30 patients with osteoarthritis and moderate chronic periodontitis $(\mathrm{CP}+\mathrm{OA}), 30$ patients of both sexes aged 35-50 years with moderate chronic periodontitis alone (CP). And control group (C) of 20 healthy patients with healthy periodontium participated in this cross sectional study. we excluded the postmenopausal and pregnant woman from female patient and smoker patient also. All patients are free of medication and have good general health with no history of systemic disease. Participants with OA have documentation or radiographic imaging, consistent with degenerative arthritis in the absence of an inflammatory condition. Venous blood samples were drawn from each subject using pyrogen-free heparinized collection tubes. Tubes were centrifuged according to the manufacturer's guidelines, then stored at $15^{\circ} \mathrm{C}$ till analyse. serum TNFa and hs CRP were measured using an enzyme-linked immunosorbent assay (ELISA).

Results: A non-significant differences between studied group regarding serum level of hsCRP and TNF-a, as well as, the result revealed that the median of serum levels of hSCRP were little higher in chronic periodontitis with osteoarthritis group than chronic periodontitis group and control groups represent as 0.31, 0.29, and 0.24. Similarly, the medium serum level of TNFa was higher in chronic periodontitis with OAthan in other two groups $(10.615,10.533$, and 9.682 respectively). The age and gender showed a non-significant difference between the groups

Conclusion: The present study revealed that there's a strong positive correlation between serum levels of hsCRP and TNFa in patients of all groups but there is no correlation between Osteoarthritis and chronic periodontitis.

Keywords: chronic periodontitis, osteoarthritis, TNFa, hsCRP. (J Bagh Coll Dentistry 2018; 30(3): 7-12)
\end{abstract}

\section{INTRODUCTION}

$\mathrm{PD}$, is considered one of the common oral diseases, it is a destructive inflammatory disorder affecting the tissues that support teeth and it is mostly associated with range of pathogenic bacteria (Porphyromonas gingivalis, Tannerella forsythia, Prevotella intermedia together with Aggregatibacteractinomycetem-comitans) ${ }^{(1)}$, PD is characterized by both chronic inflammation of connective tissue and alveolar bone destruction which lead to loss of tooth-supporting apparatus (2). Sequentially, PD followed gingivitis, which involves inflammation of marginal periodontium. However, not every gingivitis develops into PD. The progression of the periodontal destruction depends on the quantity, quality, virulence of the microorganisms and the immune response of the host $^{(\mathbf{1})}$.

$\mathrm{OA}$ is the most important reason of disability in musculoskeletal worldwide ${ }^{(3)}$, and the major factor in physical limitation of old people. ${ }^{(4)}$

(1) Ministry of health, Baghdad, Iraq

(2) Assistant Professor, Department of Periodontics, College of Dentistry, University of Baghdad.

(3) Lecturer Department of oral Surgery and PeridontologyCollege of Dentistry- Al Mustansryia University
Also, it is a chronic joint disease that has compound etiologies characterized with synovial inflammation, remodeling of subchondral bone, and produce osteophytes, which in turn cause cartilage deterioration, Severity of OA afflicted functional ability. ${ }^{(5)}$. Hence, $\mathrm{OA}$ in most of people leads to maintain proper oral hygiene, lead to accumulation of plaque and calculus, which increases hazard of dental caries and periodontal disease ${ }^{(6)}$. Cytokinesact as a communication between immune and non-immune cells ${ }^{(7)}$. It has been proposed that cytokines are necessary to the pathogenesis of many diseases ${ }^{(8)}$. C-reactive protein is a systemic marker released during the acute phase of an inflammatory response. Creactive protein is produced by the liver and is regulated by circulating cytokines, such as TNF $\alpha$ and interleukin- 1, from local and/or systemic inflammation such as periodontal inflammation (9). TNF $\alpha$ is a critical pro-inflammatory mediator that results in destruction of periodontal tissues. TNFa has many

actions mostly pro-inflammatory. Leukocyte recruitment and vascular permeability are facilitated by stimulating expression of selectins and adhesins by TNF- $\alpha$, activating the osteoclasts 
similarly to way with IL-1 lead to resorption of bone and extracellular matrix. Monocytes and macrophages are the most important cell types producing TNF- $\alpha^{(\mathbf{1 0})}$. These cytokines are normally found in the blood and increase with inflammation so in this study we determine the level of $\mathrm{TNF} \alpha$ and hsCRP in the serum of the patient to determine the degree of inflammation in chronic periodontitis and osteoarthritis.

\section{MATERIALS AND METHODS}

Sample population consisted of eighty male and female subjects with age range 35-50 years. Moderate chronic periodontitis with OA $(\mathrm{CP}+\mathrm{OA})$ group 30 subject seeking treatment in the rheumatology clinic in Baghdad Teaching Hospital and the $\mathrm{CP}$ groups 30 subject, with control (C) group (20 subjects) were recruited from the attendants to Iraqi National Blood Bank. The people enrolled voluntarily in the study in the period between December 2016 and March 2017. They were subjected to a questionnaire including question about their name, age, full medical history, dental history, medications and they were diagnosed for detecting a periodontal disease. Followed by blood collection for the assessment of serum level of TNF $\alpha$ and hsCRP.

Exclusion criteria: Pregnant and menopause ladies, smokers, any patient with history of other chronic systemic diseases which are known to be associated with $\mathrm{CP}$ such as cardiovascular diseases and diabetes mellitus. Also, Rheumatoid patient and PD patient who received periodontal treatment and /or antibiotics during the last 3months.

Collection of blood Samples: After the subjects have been selected,5ml of venous blood sample were aspirated from anticubital vein of each individual, using disposable plastic syringes with 23 gauge stainless steel needle. The whole blood was collected in sterile disposable plain tubes. After collection of the whole blood, centrifuging at 2, 000-3, 000rpm for 20 minutes. Then aspirated and transferred immediately into another tube and frozen at $\left(-15^{\circ} \mathrm{C}\right)$ for subsequent analysis. Haemolyzed samples were discarded. Then, using ELISA Kit (96-wells) for quantitative determination of serum human TNF- $\alpha$, hs CRP (Sunlong Biotech Co. Ltd, China) The Microelisa strip plate provided in this kit has been pre-coated with an antibody specific to TNF $\alpha$ and hsCRP. Standards or samples were added to the appropriate Microelisa strip plate wells and combined to the specific antibody.

Statistical Analysis: Each patient assigned a serial identification number. The data were reviewed, cleaned with double check entry into the computer using Statistical Package for Social Sciences (SPSS) version 21. The overall comparison of mean values among the different study groups was done by Kruskal-Wallis. Comparison between any two study groups was done by Mann-Whitney U-test. The correlation between TNF- $\alpha$, hs CRP and the clinical variables in each group was done by Spearman's correlation test.

\section{RESULTS}

In this study, 80 patients were included in 3 main groups. The first group consist of 30 patients with moderate $\mathrm{CP}+\mathrm{OA}$, second group include 30 patients with moderate $\mathrm{CP}$, third group is the $\mathrm{C}$ group consisting of 20 subjects. The age range for participants between 35-50 years. The 32 females represent $40 \%$ from the total samples and 48 males represent $60 \%$ of the total samples. From the 30 patients in $\mathrm{CP}+\mathrm{OA}$ group, 13 are males $(43.33 \%)$ and the others are females representing $56.67 \%$ of the group, but in CP group the number of females (9) and the males are 21 from this we observed that males are the dominant in this group and they represent $70 \%$ of the total samples. The $\mathrm{C}$ group, 6 females and 14 males. There were no statistical association between males and females (Table 1).

The age of the patient was 35-50 years, in C group the patient age from 35-42 represent $75 \%$ of the total patient in this group and the age from 43-50 was only represent $5 \%$ in the group. The $\mathrm{CP}+\mathrm{OA}$ group the percentage of age from $35-42$ was $43 \%$ and $43-50$ was $56 \%$, in CP group the age of the patient from $35-42$ was $53 \%$ and from 43-50 was $46 \%$. In all these groups the age distribution had no significant difference (Table 2).

The current study indicated that $\mathrm{TNF} \alpha$ exhibited little increase in $\mathrm{CP}+\mathrm{OA}$ group, the median was 10.615 as compared with $\mathrm{CP}$ group (10.533) and C group (9.682). Analysis of results using Kruskal-Wallis test showed that the difference was statistically non-significant (Table 3).

In table 4 , data showed that the hsCRP was found to be high in the $\mathrm{CP}$ with OA the median is 0.314 followed by CP (0.289), while the lowest median of CRP was in C group (0.242), and the result was statistically not significant $(\mathrm{P}>0.05)$.

There was strong positive correlation between TNF $\alpha$ and hsCRP in each study group as shown in table 5 . 
Table 1: Gender distribution among study groups.

\begin{tabular}{|c|c|c|c|c|c|c|c|c|}
\hline & \multicolumn{3}{|c|}{ Group } & \multirow{2}{*}{ Chi-square $^{\#}$} & \multirow{2}{*}{ p-value } & \multirow{2}{*}{ Total } & \multirow{3}{*}{ Sig } \\
\hline & & Control & CP. only & $\mathrm{CP}+\mathrm{OA}$ & & & & \\
\hline \multirow{3}{*}{ Male } & NO. & 14 & 21 & 13 & \multirow{6}{*}{5.556} & \multirow{6}{*}{0.062} & 48 & \\
\hline & $\%$ & 70.00 & 70.00 & 43.33 & & & 60.00 & \\
\hline & $\%$ Total & 17.50 & 26.25 & 16.25 & & & 60.00 & \multirow{4}{*}{ NS } \\
\hline \multirow{3}{*}{ Female } & NO. & 6 & 9 & 13 & & & 32 & \\
\hline & $\%$ & 30.00 & 30.00 & 56.67 & & & 40.00 & \\
\hline & $\%$ Total & 7.50 & 11.25 & 21.25 & & & 40.00 & \\
\hline
\end{tabular}

Table 2: Age distribution among study groups.

\begin{tabular}{|c|c|c|c|c|c|c|c|}
\hline & \multicolumn{3}{|c|}{ Group } & \multirow{2}{*}{ Chi-square $^{\#}$} & \multirow{2}{*}{ Sig. } & \multirow{2}{*}{ Total } \\
\hline & & Control & CP. Only & $\mathrm{CP}+\mathrm{OA}$ & & & \\
\hline \multirow{3}{*}{$\begin{array}{l}35-42 \\
\text { Years }\end{array}$} & NO. & 15 & 16 & 13 & \multirow{6}{*}{4.916} & \multirow{6}{*}{$\begin{array}{c}0.086 \\
\text { NS }\end{array}$} & 44 \\
\hline & $\%$ & 75.00 & 53.33 & 43.33 & & & 55.00 \\
\hline & $\%$ Total & 18.75 & 20.00 & 16.25 & & & 55.00 \\
\hline \multirow{3}{*}{$\begin{array}{c}43-50 \\
\text { Years }\end{array}$} & NO. & 5 & 14 & 17 & & & 36 \\
\hline & $\%$ & 25.00 & 46.67 & 56.67 & & & 45.00 \\
\hline & $\%$ Total & 6.25 & 17.50 & 21.25 & & & 45.00 \\
\hline
\end{tabular}

Table 3: Illustrates the analytic test of TNF $\alpha$.

\begin{tabular}{|c|c|c|c|c|c|c|c|c|}
\hline \multirow[b]{2}{*}{ Group } & \multirow[b]{2}{*}{ Min. } & \multirow[b]{2}{*}{ Max. } & \multirow[b]{2}{*}{ Mean } & \multirow[b]{2}{*}{$\pm \mathrm{SD}$} & \multirow[b]{2}{*}{ Median } & \multirow[b]{2}{*}{ Mean Rank } & \multicolumn{2}{|c|}{ Kruskal-Wallis } \\
\hline & & & & & & & $\mathrm{X}^{2}$ & Sig. \\
\hline Control & 5.036 & 34.550 & 11.125 & 6.331 & 9.682 & 38.88 & \multirow{3}{*}{0.131} & \multirow{3}{*}{$\begin{array}{c}0.937 \\
\text { NS }\end{array}$} \\
\hline CP only & 4.552 & 26.557 & 10.662 & 4.387 & 10.533 & 41.08 & & \\
\hline $\mathrm{CP}+\mathrm{OA}$ & 4.552 & 16.375 & 10.190 & 2.948 & 10.615 & 41.00 & & \\
\hline
\end{tabular}

Table 4: Illustrates the analytic test for hsCRP.

\begin{tabular}{|c|c|c|c|c|c|c|c|c|c|}
\hline \multirow{2}{*}{ Group } & \multirow{2}{*}{ Min. } & \multirow{2}{*}{ Max. } & \multirow{2}{*}{ Mean } & \multirow{2}{*}{ \pm SD } & \multirow{2}{*}{ Median } & \multirow{2}{*}{ Mean Rank } & \multicolumn{2}{|c|}{ Kruskal-Wallis } & \multirow[t]{2}{*}{ Sig } \\
\hline & & & & & & & $\mathbf{X}^{2}$ & p-value & \\
\hline Control & 0.101 & 1.681 & 0.334 & 0.335 & 0.242 & 33.25 & \multirow{3}{*}{2.894} & \multirow{3}{*}{0.235} & \multirow{3}{*}{ NS } \\
\hline CP only & 0.117 & 1.052 & 0.316 & 0.164 & 0.289 & 41.28 & & & \\
\hline $\mathrm{CP}+\mathrm{OA}$ & 0.122 & 3.023 & 0.389 & 0.504 & 0.314 & 44.55 & & & \\
\hline
\end{tabular}

Table 5: Illustrates the correlation of TNF $\alpha$ and hsCRP among study groups.

\begin{tabular}{|c|c|c|c|}
\hline Groups & $\mathbf{R}$ & P-value & Sig \\
\hline Control & 0.512 & 0.021 & S \\
\hline CP & 0.581 & 0.001 & HS \\
\hline CP+OA & 0.694 & 0.000 & HS \\
\hline
\end{tabular}

\section{DISCUSSION}

OA occurs in the population with a high incidence about in fourth decade of life. Supporting the above fact, the groups of OA patients in the current study consisted of more females between 35-50 years, in $\mathrm{CP}+\mathrm{OA}$ group, $\mathrm{CP}$ group the number of female was $26(40 \%)$, and number of male 34 (60\%), while the C group consisted of 6 females and 14 males. Statistical analysis showed that there were non-significant differences regarding gender and these demographic data is coinciding with a study done in Europe by Lugonja et al. (11) they mentioned that no significant difference in terms of gender and age between $\mathrm{CP}+\mathrm{OA}$ group and $\mathrm{CP}$ group and also agree with study of Torkzaban et al. ${ }^{(\mathbf{1 2})}$ which found no correlation between gender and any of periodontal indices. this study disagrees with the study done by Pokrajac-Zirojevic et al. ${ }^{(13)}$ which found the association between OA and gender was proven to be highly significant with female more commonly affected with $\mathrm{OA}$ than male $(\mathrm{P}=0.001)$.

Interestingly, the present study reported non-significant correlation of TNF $\alpha$ among the groups, although TNF $\alpha$ was increased in $\mathrm{OA}+\mathrm{CP}$ group more than $\mathrm{CP}$ and $\mathrm{C}$ group, $\mathrm{TNF} \alpha$ has an important role in inflammatory arthritis and in degenerative joint disease ${ }^{(14)}$ it may be from the fact that human articular 
chondrocytes from OA cartilage expressed a significantly higher number of the p55 TNF $\alpha$ receptor which could make OA cartilage particularly susceptible to TNF $\alpha$ degradative stimuli ${ }^{(15)}$. also associated with the level of OA severity. It is known that TNF $\alpha$ induces bone and extracellular matrix resorption by activating the osteoclasts, also it is secreted by leukocyte, macrophage, lymphocyte in the local lesion of PD. (16) This agree with Fernandes et al. ${ }^{(17)}$ who observed that high serum levels of TNF $\alpha$ detected in patients with $\mathrm{CP}$.

so it was clear that their levels increased in $\mathrm{OA}$ and periodontal disease but in this study the difference was statistically nonsignificant which may be related to the newly diagnosed disease, OA is a noninflammatory disease, and the proinflamatory $\mathrm{TNF} \alpha$ level is still less in the serum of the patient and may be the severity of PD had moderate effect on the destruction of the supporting tissue which is reflected on the level of inflammatory markers in the serum.

Also, in this study the hsCRP was nonsignificant related among the study groups but it was higher in $\mathrm{OA}+\mathrm{CP}$ group than $\mathrm{CP}$, $\mathrm{C}$ group. CRP, is a protein mainly produced by the liver in response to an increase in interleukin- 6 and TNFa, which is part of the non-specific response to inflammation, infection and tissue damage ${ }^{(\mathbf{1 8})}$. There is a strong evidence that individuals with $\mathrm{CP}$ have elevated CRP levels as compared to the $\mathrm{C}$ groups which agrees with Previous studies conducted by Martu et al. and Salzberget al. ${ }^{(19)}$. CPR is related to the initial host response to injuries, infections, ischemic necrosis or malignancy. It is initiated by the activation of local macrophages and other cells (including fibroblasts and endothelial cells), leading to the release of mediators such as TNFa, IL-6 and IL-13. These in turn cause systemic changes including hepatic release of a range of plasma proteins (including CRP), activation of complement proteins and various metabolic changes. ${ }^{(20)}$ This result disagrees with the study of Beck et al. ${ }^{(21)}$ whom assessed the relationship between CRP and the periodontal status was not as clear. In spite of lack of previous study about the serum level of hsCRP and TNF $\alpha$ in patient with moderate $\mathrm{CP}$ and $\mathrm{OA}$, this study indicated anon-significant correlation between the markers in the study groups, it may be due to differences that can be influence CRP level such as different level of inflammation regarding $\mathrm{OA}$ or amount of adipose tissue or the effect of body mass index (BMI), high blood pressure, alcohol use, chronic fatigue, diabetes, sleep disturbances, depression, lifestyle, in addition diet may fluctuate CRP level. Other factors can have influence on proinflammatory cytokine production and/or activity are the cytokines having antiinflammatory properties. For such cytokines, namely transforming growth factor (TGF) $\alpha$, IL-4, IL-10 and IL-13, have been identified as modulator for various inflammatory processes.

This study found a strong positive correlation between TNF $\alpha$ and CRP in each group which agree with Foss et al. ${ }^{(22)}$ whom revealed a positive correlation between the level of TNF $\alpha$ and hsCRP that indicate when patients have high TNFa levels, a proportional increase in CRP concentrations also occurs, this correlation considered that when the onset of acute-phase inflammatory response changes the concentrations of many plasma proteins, reflecting reorganization of the gene expression of hepatocyte secretory proteins after the inflammatory stimulus hsCRP is the acute phase protein occurring in humans, Normally, these proteins are present in small amounts in plasma, and an exacerbated increase in their rate of synthesis occurs after stimulation. A progressively increasing number of hepatocytes are recruited for CRP synthesis during the first days after the inflammatory reaction. Thus, persistently elevated CRP levels reflect active disease, and have been reported to occur in several infections, inflammatory reactions, tumors, and lesions. As conclusion of this study, CP and OA showed no significant association in overall analysis. Findings from this cross-sectional study do not provide evidence for a correlation between CP and OA. Prospective research and studies using clinical criteria for diagnosis of symptomatic OA are needed to confirm these findings.

\section{REFERENCES}

1. Saini $R$, Marawar $P$, Shete $S$, Saini $S$. Periodontitis, a true infection. J Global Inf Dis. 2009;1(2):149-50.

2. DeStefano F, Anda RF, Kahn HS, Williamson DF, Russell CM. Dental disease and risk of coronary heart disease and mortality. BMJ. 1993;306(6879):688-91. 
3. Ganley TJ, Flynn JM, Scott WN. Insall Scott Surgery of the Knee.

4. Cheng YJ, Hootman JM, Murphy LB, Langmaid GA, Helmick CG. Centers for Disease Control and Prevention (CDC) Prevalence of doctor-diagnosed arthritis and arthritis-attributable activity limitation-United States, 2007-2009. MMWR Morb Mortal Wkly Rep. 2010;59(39):1261-5.

5. El-Sherif HE, Kamal R, Moawyah O. Hand osteoarthritis and bone mineral density in postmenopausal women; clinical relevance to hand function, pain and disability. Osteoarthritis Cartilage. 2008;16(1):12-7.

6. Pokrajac-Zirojevic V, Slack-Smith LM, Booth D. Arthritis and use of dental services: a population based study. Austr Dent J. 2002; 47(3):208-13.

7. Kinane, DF, Lindhe J. Pathogenesis of periodontitis. Clinical periodontology and implant dentistry. $3^{\text {rd }}$ ed. Copenhagen: Munksgaard, 1997. pp.189-222

8. Gemmell E, Carter CL, Seymour GJ. Chemokines in human periodontal disease tissues. Clin Exper Immun. 2001;125(1):134-41.

9. D'aiuto F, Nibali L, Parkar M, Suvan J, Tonetti M. Short-term effects of intensive periodontal therapy on serum inflammatory markers and cholesterol. J Dent Res. 2005;84(3):269-73

10. Moreland LW, Baumgartner SW, Schiff MH, Tindall EA, Fleischmann RM, Weaver AL, et al. Treatment of rheumatoid arthritis with a recombinant human tumor necrosis factor receptor (p75)-Fc fusion protein. New England J Med. 1997;337(3):141-7.

11. Lugonja B, Yeo L, Milward MR, Smith D, Dietrich T, Chapple IL, et al. Periodontitis prevalence and serum antibody reactivity to periodontal bacteria in primary Sjögren's syndrome: a pilot study. J Clin Periodontol. 2016; 43(1):26-33.

12. Torkzaban P, Hjiabadi T, Basiri Z, Poorolajal J. Effect of rheumatoid arthritis on periodontitis: a historical cohort study. J Periodont Implant Sci. 2012;42(3):67-72.

13. Pokrajac-Zirojevic V, Slack-Smith L, Booth D. Arthritis and use of dental services: a population based study. Austr Dent J. 2002; 47(3):208-13.
14. Westacott CI, Sharif M, editors. Cytokines in osteoarthritis: mediators or markers of joint destruction? Seminars in arthritis and rheumatism; 1996: Elsevie.

15. Fernandes JC, Martel-Pelletier J, Pelletier JP. The role of cytokines in osteoarthritis pathophysiology. Biorheology 2002;39(12): 237-46.

16. Zhou SY, Duan XQ, Hu R. Effect of nonsurgical periodontal therapy on serum levels of TNF- $\alpha$, IL-6 and C-reactive protein in periodontitis subjects with stable coronary heart disease. Chin J Dent Res. 2013;16(2):145-51.

17. Ieremie Y, Maria L, Lazăr L, Ciurba A. Diagnostic and prognostic particularities of the implications of the presence of tumor necrosis factor alpha in patients with periodontal disease. Acta Medica Marisiensis. 2014; 60(6): 275-7.

18. Martu S, Nicolaiciuc OV, Solomon S, Sufaru I, Scutariu MO, Rezus C, Popescu EU. The evaluation of the $\mathrm{c}$ reactive protein levels in the context of the periodontal pathogens presence in cardiovascular risk patients. Rev Chem (Bucharest). 2017;68(5):1081-4.

19. Salzberg TN, Overstreet BT, Rogers JD, Califano JV, Best AM, Schenkein HA. Creactive protein levels in patients with aggressive periodontitis. J Periodontol. 2006; 77(6): 933-9.

20. Ide M, McPartlin D, Coward PY, Crook M, Lumb P, Wilson RF. Effect of treatment of chronicperiodontitison levels of serum markers of acute-phase inflammatory and vascular responses. J Clin Periodontol. 2003; 30(4): 33440.

21. Beck JD, Slade G, Offenbacher S. Oral disease, cardiovascular disease and systemic inflammation. Periodontol 2000. 2000; 23(1): 110-20.

22. Foss NT, De Oliveira EB, Silva CL. Correlation between TNF production, increase of plasma $\mathrm{C}$ reactiveprotein level and suppression of $\mathrm{T}$ lymphocyte response to concanavalin A during erythema nodosum leprosum. Int J Leprosy Mycobact Dis. 1993;61:218.

الخلفية: التهاب اللثة هو مرض التهابهي مزمن يؤثر على اربطة وانسجة ما حول الاسنان والعظم السنخي، التهاب المفاصل هو ايضا

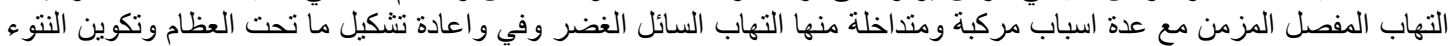

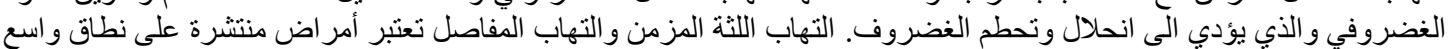

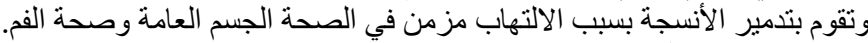

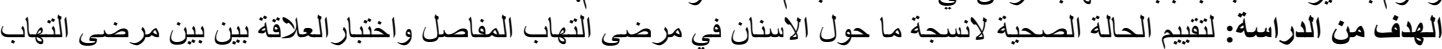

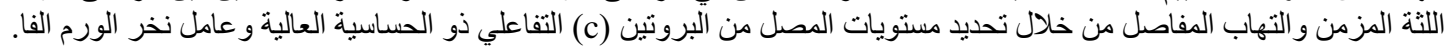

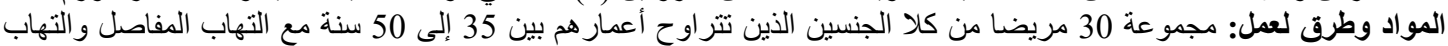

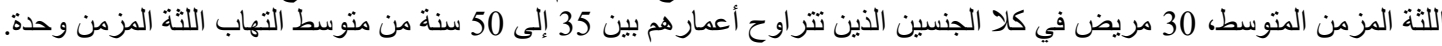

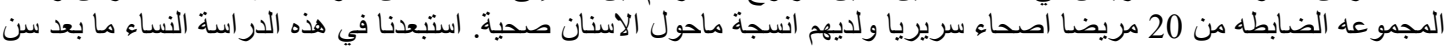

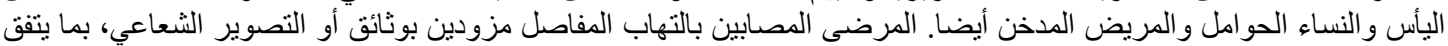

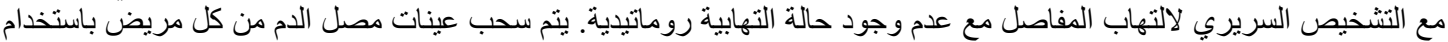

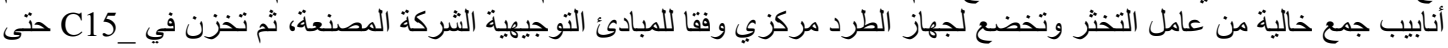

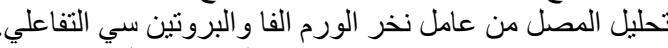

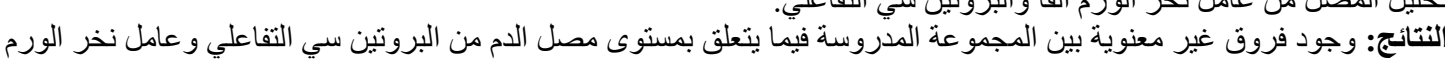

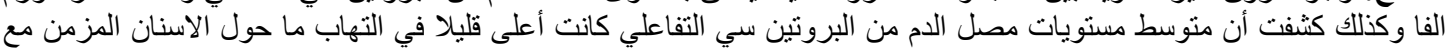




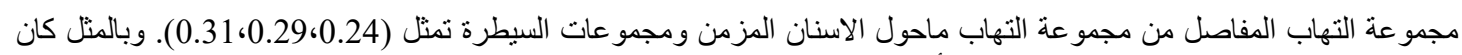

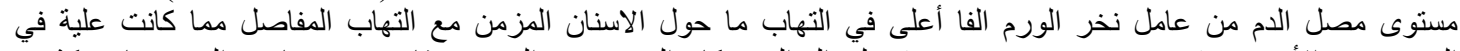

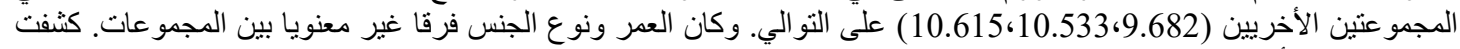

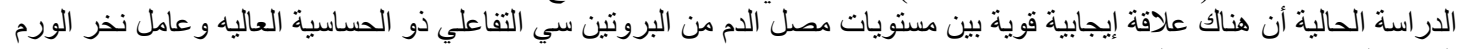

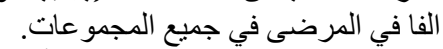

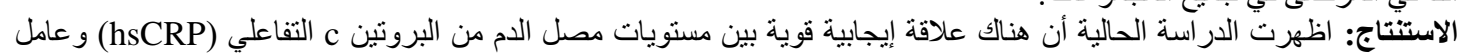

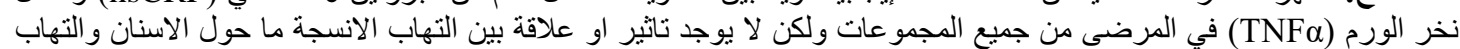

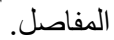

